\title{
Comparing the effect of group- based training along with text messaging and compact disc- based training on men's knowledge and attitude about participation in perinatal care: a cluster randomized control trial
}

\author{
Vahideh Firouzan ${ }^{1}$, Mahnaz Noroozi ${ }^{2 *}$ D, Mojgan Mirghafourvand ${ }^{3}$ and Ziba Farajzadegan ${ }^{4}$
}

\begin{abstract}
Background: Men's participation in perinatal care is one of the key factors in promoting maternal and neonatal health. The effects of various methods of training on men's knowledge and attitude about participation in perinatal care can be different. So, this study aimed to compare the effect of two methods of training on men's knowledge and attitude about participation in perinatal care.

Methods: This cluster randomized control trial was conducted in three midwifery clinics in Tabriz, Iran between May and August 2018. Each clinic was randomly assigned to intervention (group- based training along with text messaging and CD- based training) and control groups. Seventy-five men were enrolled in three groups and evaluated for their knowledge and attitude about participation in perinatal care. Before and 3 months after the intervention, a researcher-made questionnaire was completed by the participants. Data were analyzed using descriptive and inferential statistics (paired t-test, one-way ANOVA, ANCOVA, chi-square, Kruskal-Wallis and Fisher exact tests).

Results: The mean (SD) score of men' $s$ knowledge and attitude about participation in perinatal care had a significant increase in group- based training along with text messaging after the intervention compared to the score of before the intervention ( $p<0.001, p=0.005$, respectively), but the mean (SD) score of men's knowledge and attitude had not a significant increase in CD- based training and control group after the intervention compared to the score of before the intervention. The mean (SD) score of men's knowledge and attitude about participation in perinatal care in group- based training along with text messaging were significantly higher than in CD- based training ( $p<0.001, p=0.039$, respectively) and control group ( $p=0.001, p=0.021$, respectively) after the intervention, respectively. However, the mean (SD) score of men' $s$ knowledge and attitude in CD- based training were not significantly different from the control group after the intervention.

(Continued on next page)
\end{abstract}

\footnotetext{
* Correspondence: noroozi@nm.mui.ac.ir

${ }^{2}$ Department of Midwifery and Reproductive Health, School of Nursing and Midwifery, Isfahan University of Medical Sciences, Isfahan, Iran

Full list of author information is available at the end of the article
}

C C The Author(s). 2020 Open Access This article is licensed under a Creative Commons Attribution 4.0 International License, which permits use, sharing, adaptation, distribution and reproduction in any medium or format, as long as you give appropriate credit to the original author(s) and the source, provide a link to the Creative Commons licence, and indicate if changes were made. The images or other third party material in this article are included in the article's Creative Commons licence, unless indicated otherwise in a credit line to the material. If material is not included in the article's Creative Commons licence and your intended use is not permitted by statutory regulation or exceeds the permitted use, you will need to obtain permission directly from the copyright holder. To view a copy of this licence, visit http://creativecommons.org/licenses/by/4.0/. The Creative Commons Public Domain Dedication waiver (http://creativecommons.org/publicdomain/zero/1.0/) applies to the data made available in this article, unless otherwise stated in a credit line to the data. 
(Continued from previous page)

Conclusion: Group- based training along with text messaging was more effective in improving the knowledge and attitude of men about participation in perinatal care compared to CD- based training. So, its implication in educational programs for the men is recommended.

Trial registration: IRCT, IRCT20160224026756N4. Registered 27 May 2018.

Keywords: Group-based training, Compact disk-based training, Perinatal care, Participation, Knowledge, Attitude, Men

\section{Background}

Men's participation in perinatal care is one of the key factors in promoting maternal and neonatal health $[1,2]$. In most parts of the world, men in the family are responsible for important choices about allocating financial resources and caring behaviors which directly affect the health of women and infants [3]. Although it has been found that men's behavior affects the reproductive health of their wives and infants, most maternal and child health programs have focused on women's participation and education, with men being ignored. Men do not have access to information that helps them make informed decisions and improve their wives' health [4]. According to studies, various factors influence men's participation in perinatal care. These factors are at different levels including community, health care system, family, and individual level [5-8]. These include perceptions, beliefs, and attitudes toward women's health as a feminine task, leading to poor male participation in women's reproductive health [2, 6-11]. Further, some of the known individual barriers including men's education level, income, and limited awareness of men's role in reproductive health, hinder this partnership [1, 5-8]. A study to illuminate expectant first-time fathers' experiences of participation during pregnancy in three Nordic countries (Denmark, Finland and Sweden) showed that fathers wanted to participate and be responsible from the beginning of pregnancy [12]. The men's need to education to enhance participation in prenatal, delivery, and postnatal care as well as its positive effects on maternal and neonatal health has been shown in numerous studies in different countries [1,13-18]. The results of a study in rural areas of Pakistan showed that training men to increase their participation in perinatal care would improve some maternal and neonatal health indicators [19]. Adeleye and Okonkwo showed that trained men were more likely to recognize a danger sign of pregnancy and delivery [20]. Also, a study in Bangladesh showed a significant relationship between men's education and their active participation in perinatal care [21]. In addition, the results of a study showed that men's participation in prenatal counseling sessions increased their engagement in postpartum care, duration of exclusive breastfeeding, use of contraceptive methods, improving couples' relationships and shared decision making [22].
Following the Cairo international conference on population and development (ICPD) in 1994, the positive role of men has been emphasized to promote reproductive health as well as to achieve the millennium development goals (MDGs) including maternal health, gender equality, reducing child mortality, eradicating illiteracy and diseases [23]. In Iran, no policies or programs exist that encourage participation of men in the perinatal period. In recent years, because of efforts to encourage women to have vaginal delivery, "delivery preparation classes" have been conducted for pregnant women including one session in which the men participate. Practically, however, this is executed at a limited number of health centers and its execution is not problem-free [2]. The effects of various methods of training on men's knowledge and attitude about participation in perinatal care can be different. Group education is a method for stimulate thinking, challenging the beliefs and training interpersonal skills and if the learners would be ready for participating in the discussion the education would have an acceptable success [24]. Another training method is teaching through compact disks (CDs) which would be applied by transferring the concepts using texts, audio, images and video, more simply, extensive, and attractive [25]. Since no study has been conducted to compare the effect of different methods of training on men's knowledge and attitude about participation in perinatal care in Iran, therefore, this study aimed to determine and compare the effect of two methods of group- based training along with text messaging and compact disc (CD) - based training, on men's knowledge and attitude about participation in perinatal care.

\section{Methods}

CONSORT guidelines were adhered for reporting of this trial.

\section{Study design}

This study was a cluster randomized control trial with three groups (intervention 1, intervention 2 and control groups). The population of this study includes husbands of pregnant women (with gestational age of 20-22 weeks) who referred to three midwifery clinics affiliated to the Social Security Organization of Tabriz city, East Azerbaijan province, Iran from May to August 2018. 
There were a large number of pregnant women and their husbands with the same socio-economic status who referred to these clinics. Also, it was easier to access pregnant women and their husbands in these places. In this study to determine how many samples are needed to create a good chance of finding an effect (if the effect really exists) and considering that the minimum recommended value for the test power is $80 \%$, we considered a test power of $95 \%$. Based on the confidence interval of $95 \%$, a test power of $95 \%$ (using G-power software), and considering a sample loss rate of $10 \%$, sample size of 24 was estimated for each group.

\section{The inclusion and exclusion criteria}

The inclusion criteria were husbands of pregnant women with gestational age of 20-22 weeks, lack of participation of men in any educational intervention or training about men's participation in perinatal care, living with their wife, and no problem in relationships between couples (by asking participants). The exclusion criteria were unwillingness to continue to cooperate at any stage of the research and lack of full participation of men in the training sessions held in group- based training along with text messaging.

\section{Procedures}

In the present study for preventing interactions and relationships between participating men about the interventions, the three midwifery clinics were randomly assigned to intervention (group- based training along with text messaging and $\mathrm{CD}$ - based training (and control groups by first author (VF). In this regard, one of the midwifery clinics was selected for group- based training along with text messaging, another clinic for CD- based training group and third clinic for control group. In the midwifery clinics, using convenience sampling, the medical files of 120 pregnant women were evaluated and participants who had the inclusion criteria were selected (Fig. 1). Then, after making phone calls to them, other inclusion criteria were asked and the time for their husband visit was settled. After visiting 75 eligible men and assuring them of the confidentiality of their information, written informed consent was obtained from all the participants (Fig. 1). The researcher performed the groupbased training using different training methods (speech, displaying images, sharing the members' experiences, and question and answer), board and computer in two sessions each lasting for $2 \mathrm{~h}$ with one-week interval on Fridays. At the end of the second session, the men were notified to receive health messages via mobile at their desired time. From the day after the second group education session, three to four health text messaging were sent weekly (about the participation of men in perinatal care) up to 3 months after the intervention. After the second group training session, the researcher distributed a $\mathrm{CD}$ among men of the $\mathrm{CD}$-based training group about men participation in perinatal care (contents were similar to those provided at group-based training). This $C D$ consisted of the training text, questions, images, and voices. Training content included changes in women's body during pregnancy and the role of men in women's adaption to these changes; common complaints during pregnancy and men's role in women adaption to them; the men's participatory role in perinatal care; the father's relationship with the fetus and the mother; preparation for childbirth and fatherhood; danger signs during pregnancy and how to deal with them; the role of men in delivery process; social support and its consequences during pregnancy, childbirth and postpartum; The role of men in providing social support for pregnant women, during childbirth and postpartum; psychological support for pregnant women and in postpartum period; postpartum grief and men's supportive role; postpartum depression and the role of men; barriers to men's participation during pregnancy, childbirth, and postpartum and its remedies. Valid scientific books, articles, and websites were applied for preparation of the training contents [2, 26-31]. In this study, no action was taken for the control group.

\section{Primary outcomes}

The primary outcomes included men's knowledge and attitude about their participation in perinatal care that were measured by a researcher-made questionnaire. The content of questions on men' $s$ knowledge and attitude about their participation in perinatal care were based on training content. This questionnaire was completed by the participants at two stages (before the intervention and 3 months after the intervention). The aforesaid questionnaire contained three sections: demographic characteristics, knowledge measurement, and attitude measurement. Knowledge measurement tool consisted of 28 multiple choice questions and the score of one was assigned to each "correct" answer. For "incorrect" and "not sure" answers, a score of zero was considered. The minimum score of zero and the maximum score of 28 were considered for the knowledge measurement tool. An example of a knowledge assessment question was: "When a man talks to his pregnant wife about her worries, it reduces her anxiety". Attitude measurement tool had 23 questions with 5-point Likert scale (totally agreed, agreed, I have no idea, disagreed, totally disagreed). The assigned scores for measuring negative attitude were: 0 for totally agreed, 1 for agreed, 2 for I have no idea, 3 for disagreed and 4 for totally disagreed. Furthermore, the assigned scores for measuring positive attitude were: 4 for totally agreed, 3 for agreed, 2 for I have no idea, 1 for disagreed and 0 for totally disagreed. 


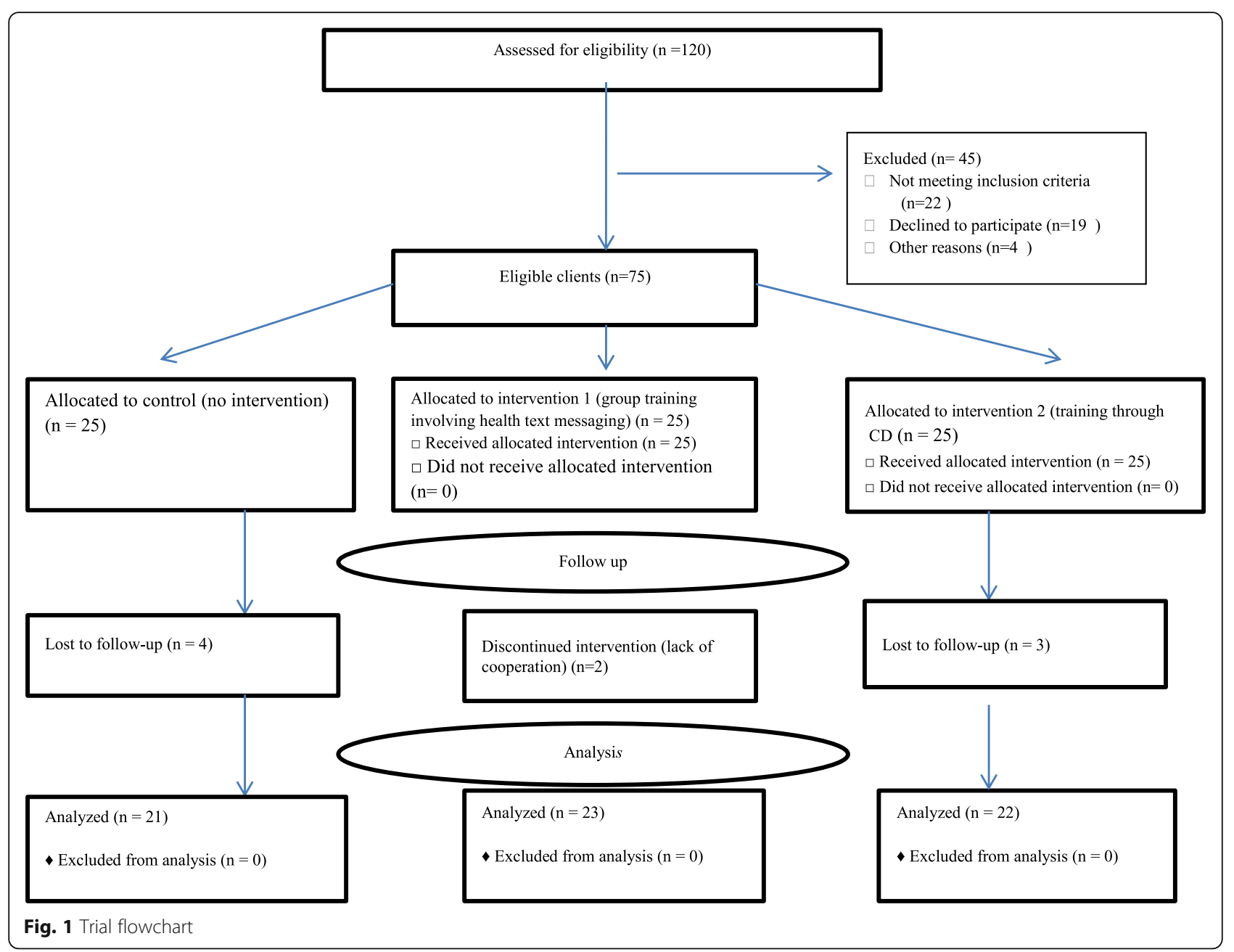

The minimum score of zero and the maximum score of 92 were considered for the attitude measurement tool. An example of an attitude assessment question was: "The duty of a man during pregnancy and postpartum is just work outside the home and earning an income".

Content validity method was used to approve the validity of the data collection tools and test-retest method was applied for its reliability. Cronbach's alpha coefficients for knowledge and attitude questionnaires were 0.71 and 0.89 , respectively. The intra-cluster correlation coefficients (ICC) for knowledge and attitude questionnaires were 0.88 (95\% CI $=0.59-0.96)$ and 0.98 (95\% $\mathrm{CI}=0.94-0.99)$, respectively that indicated the stability of the questionnaires.

\section{Statistical analysis}

Statistical analysis of the present study was conducted using SPSS 23 software. The Chi-square, one-way ANOVA, Kruskal-Wallis and Fisher's exact tests were used for assessing the consistency of the three groups in terms of socio-demographic characteristics. To compare mean score of men's knowledge and attitude about participation in perinatal care in each group paired t-test was used before and after the intervention. To compare the mean score of men's knowledge and attitude about participation in perinatal care between the three groups one-way ANOVA was used before the intervention. To compare the mean score of men's knowledge and attitude about participation in perinatal care between the three groups ANCOVA test was used after the intervention. The significance level for statistical tests was considered less than $0.05(P<0.05)$.

\section{Ethical considerations}

This study was registered in the registry for clinical trials (IRCT20160224026756N4). The Ethics Committee of Isfahan University of Medical Sciences approved the protocol of this study (code number: IR.MUI. Rec.1395.3.599) and written informed consent, anonymity, confidentiality and the right of leaving the research at any desired time were preserved. 
Table 1 Comparison of socio-demographic characteristics of the participants between the three groups

\begin{tabular}{|c|c|c|c|c|}
\hline Variable & $\begin{array}{l}\text { Group- based training along } \\
\text { with text messaging } \\
n=23 \\
\text { number (percentage) }\end{array}$ & $\begin{array}{l}\text { CD- based training } \\
n=22 \\
\text { number (percentage) }\end{array}$ & $\begin{array}{l}\text { Control group } \\
n=21 \\
\text { number (percentage) }\end{array}$ & $P$-value* \\
\hline \multicolumn{5}{|l|}{ Age (years) } \\
\hline$>21$ & $0(0)$ & $1(4.5)$ & $1(4.8)$ & \\
\hline $26-30$ & $5(21.7)$ & $7(31.9)$ & $4(19)$ & \\
\hline $31-35$ & $12(52.1)$ & $8(36.4)$ & $11(52.4)$ & 0.837 \\
\hline $36-40$ & $3(13.1)$ & $4(18.1)$ & $4(19)$ & \\
\hline $41-45$ & $3(13.1)$ & $2(9.1)$ & $1(4.8)$ & \\
\hline \multicolumn{5}{|l|}{ Spouse age (years) } \\
\hline$>21$ & $1(4.3)$ & $2(9.1)$ & $1(4.8)$ & \\
\hline $21-25$ & $6(26.1)$ & $3(13.6)$ & $2(9.6)$ & \\
\hline $26-30$ & $10(43.4)$ & $10(45.5)$ & $6(28.6)$ & 0.48 \\
\hline $31-35$ & $3(13.1)$ & $4(18.2)$ & $10(47.6)$ & \\
\hline $36-40$ & $3(13.1)$ & $3(13.6)$ & $2(9.6)$ & \\
\hline \multicolumn{5}{|l|}{ Number of children } \\
\hline 0 & $17(73.9)$ & $15(68.2)$ & $14(66.7)$ & \\
\hline 1 & $5(21.7)$ & $5(22.7)$ & $5(23.8)$ & 0.077 \\
\hline 2 & $1(4.3)$ & $2(9.3)$ & $2(9.5)$ & \\
\hline \multicolumn{5}{|l|}{ Education level } \\
\hline Elementary & $2(8.7)$ & $2(9.1)$ & $1(4.8)$ & \\
\hline Intermediate & $1(4.3)$ & $2(9.1)$ & $2(9.5)$ & \\
\hline Highschool & $4(17.4)$ & $4(18.2)$ & $4(19)$ & 0.807 \\
\hline Diploma & $7(30.4)$ & $6(27.3)$ & $8(38.1)$ & \\
\hline Academic & $9(39.1)$ & $8(36.4)$ & $6(28.6)$ & \\
\hline \multicolumn{5}{|l|}{ Job } \\
\hline Employee & $3(13)$ & $6(27.3)$ & $6(28.6)$ & \\
\hline Worker & $7(30.4)$ & $6(27.3)$ & $4(19)$ & 0.556 \\
\hline Freelancer & $7(30.4)$ & $8(36.4)$ & $9(42.9)$ & \\
\hline Other & $6(26.1)$ & $2(9.1)$ & $2(9.5)$ & \\
\hline \multicolumn{5}{|l|}{ Spouse education level } \\
\hline Elementary & $1(4.3)$ & $1(4.5)$ & $0(0)$ & \\
\hline Intermediate & $2(8.7)$ & $2(9.1)$ & $1(4.8)$ & 0.781 \\
\hline Highschool & $2(8.7)$ & $0(0)$ & $2(9.5)$ & \\
\hline Diploma & $5(21.7)$ & $6(27.3)$ & $8(38.1)$ & \\
\hline Academic & $13(56.5)$ & $13(59.1)$ & $10(47.6)$ & \\
\hline \multicolumn{5}{|l|}{ Spouse job } \\
\hline Housewife & $17(73.9)$ & $15(68.2)$ & $14(66.7)$ & 0.961 \\
\hline Employee & $4(17.4)$ & $4(18.2)$ & $5(23.8)$ & \\
\hline Other & $2(8.7)$ & $3(13.6)$ & $2(9.5)$ & \\
\hline \multicolumn{5}{|l|}{ Family type } \\
\hline Living with spouse and children & $20(87)$ & $21(95.5)$ & $18(85.7)$ & \\
\hline Living with spouse, children and other people & $3(13)$ & $1(4.5)$ & $3(14.3)$ & 0.611 \\
\hline \multicolumn{5}{|l|}{ Fetal sex } \\
\hline Girl & 15 (65.2) & $1(59.1)$ & $11(52.4)$ & 0.705 \\
\hline
\end{tabular}


Table 1 Comparison of socio-demographic characteristics of the participants between the three groups (Continued)

\begin{tabular}{llll}
\hline Variable & $\begin{array}{l}\text { Group- based training along } \\
\text { with text messaging } \\
\boldsymbol{n}=\mathbf{2 3} \\
\text { number (percentage) }\end{array}$ & $\begin{array}{l}\text { CD- based training } \\
\boldsymbol{n = 2 2} \\
\text { number (percentage) }\end{array}$ & $\begin{array}{l}\text { Control group } \\
\boldsymbol{n}=\mathbf{2 1} \\
\text { number (percentage) }\end{array}$ \\
\hline $\begin{array}{l}\text { Boy } \\
\text { Couples tendency to pregnancy }\end{array}$ & $8(34.8)$ & $9(40.9)$ & $10(47.6)$ \\
Male & 0 & $1(4.6)$ & $4(19)$ \\
Female & $4(17.4)$ & $3(13.6)$ & $4(19)$ \\
Both & $17(73.9)$ & $18(81.8)$ & $13(62)$ \\
Non & $2(8.7)$ & 0 & 0 \\
\hline
\end{tabular}

* $P<0.05$ was considered significant

\section{Results}

The results showed that the mean age of the men and their wives, number of children, frequency distribution of the job of men and their wives, the educational level of the men and their wives, family type, fetal sex and couples' tendency to pregnancy had no significant difference between the three groups $(p>0.05)$ (Table 1).

\section{Primary outcomes}

The results showed that the mean (SD) score of men' $s$ knowledge and attitude about participation in perinatal care were not significantly different between the three groups before the intervention $(p=0.944, p=0.228$, respectively). The results showed that the mean (SD) score of men' s knowledge $(p<0.001)$ and attitude $(p=0.005)$ about participation in perinatal care had a significant increase in group- based training along with text messaging after the intervention compared to the score of before the intervention, but the mean score of men' $s$ knowledge and attitude had not a significant increase in CD- based training and control group after the intervention compared to the score of before the intervention (Table 2). Also, the mean (SD) score of men's knowledge $(P<0.001)$ and attitude $(P=0.011)$ about participation in perinatal care had a significant difference between the three groups after the intervention (Table 3).
The results showed that the mean (SD) score of men's knowledge and attitude about participation in perinatal care in group- based training along with text messaging were significantly higher than in CD- based training ( $p<$ $0.001, p=0.039$, respectively) and control group ( $p=$ $0.001, p=0.021$, respectively) after the intervention, respectively. However, the mean (SD) score of men' $s$ knowledge and attitude in CD- based training were not significantly different from the control group (Table 4).

\section{Discussion}

This study was conducted to compare the effect of two methods of group- based training along with text messaging and compact disc (CD)- based training on men's knowledge and attitude about participation in perinatal care. The results of the present study showed that the mean score of men's knowledge and attitude about participation in perinatal care had a significant increase in group- based training along with text messaging after the intervention compared to the score of before the intervention. Although no study has been conducted on educational intervention with a combination of groupbased training and text messaging and its effect on men's knowledge and attitude about perinatal care in Iran, some studies over the impact of men's education on their knowledge and attitude about participation in perinatal care have suggested that educational interventions

Table 2 Comparing the mean scores of men's knowledge and attitude before and after the intervention in each group

\begin{tabular}{|c|c|c|c|c|c|}
\hline \multirow[t]{2}{*}{ Variable } & \multirow[t]{2}{*}{ Group } & \multirow{2}{*}{$\begin{array}{l}\text { Before the } \\
\text { intervention } \\
\text { Mean (SD) }\end{array}$} & \multirow{2}{*}{$\begin{array}{l}\text { After the } \\
\text { intervention } \\
\text { Mean (SD) }\end{array}$} & \multicolumn{2}{|c|}{ Statistical test result } \\
\hline & & & & $\mathbf{t}$ & $P$-value* \\
\hline \multirow[t]{3}{*}{ Knowledge } & Group- based training along with text messaging & $18.6(3.4)$ & $23.3(2.0)$ & -7.41 & $<0.001$ \\
\hline & CD- based training & $19(4.5)$ & $20.22(4.08)$ & -1.93 & 0.067 \\
\hline & Control group & $18.6(3.5)$ & $18.6(3.4)$ & $1 / 000$ & 0.329 \\
\hline \multirow[t]{3}{*}{ Attitude } & Group- based training along with text messaging & $64.2(9.0)$ & $68.7(9.5)$ & -3.13 & 0.005 \\
\hline & CD- based training & $66.3(13.50)$ & $67(11.24)$ & -0.70 & 0.488 \\
\hline & Control group & $69.4(8.7)$ & $69(8.6)$ & 1.36 & 0.186 \\
\hline
\end{tabular}

* $P<0.05$ was considered significant 
Table 3 Comparing the mean scores of men's knowledge and attitude after the intervention between the three groups

\begin{tabular}{|c|c|c|c|c|c|}
\hline \multirow[t]{2}{*}{ Variable } & \multirow{2}{*}{$\begin{array}{l}\text { Group- based } \\
\text { training along } \\
\text { with text } \\
\text { messaging } \\
\text { Mean (SD) }\end{array}$} & \multirow{2}{*}{$\begin{array}{l}\text { CD- based } \\
\text { training } \\
\text { Mean (SD) }\end{array}$} & \multirow{2}{*}{$\begin{array}{l}\text { Control } \\
\text { group } \\
\text { Mean } \\
\text { (SD) }\end{array}$} & \multicolumn{2}{|c|}{$\begin{array}{l}\text { Statistical test } \\
\text { result }\end{array}$} \\
\hline & & & & $F$ & $P$-value* \\
\hline Knowledge & $23.3(2.0)$ & $20.2(4.0)$ & 18.6(3.4) & 28.79 & $001 / 0>$ \\
\hline Attitude & $68.7(9.5)$ & $67.0(11.2)$ & $69.0(8.6)$ & 4.82 & 011/0 \\
\hline
\end{tabular}

${ }^{*} P<0.05$ was considered significant

have made positive changes in men's knowledge and attitude, and promoted maternal and neonatal health [32-34]. In this regard, Alawode et al. in Nigeria found increased knowledge and improved performance of men during pregnancy through mobile phone texting [35]. Also, Allport et al. believed that innovative ways to reach father involvement in children's lives are currently under investigation, including use of mobile technologies show promise in effectively engaging fathers and improving family health [36]. Kerstis et al. in Sweden showed that participating in father groups (parental classes) might help convince fathers to take more parental leave and build stronger relationships with their partner and child [37].

Adeleye and Okonkwo indicated a significant increase in knowledge and a meaningful change in attitude of men about the role of fathers in preventing maternal death through education via lectures and leaflets [20]. Researchers in a study in Bangladesh found that there was a significant relationship between active male participation in perinatal care and receiving information through TV, posters, billboards and healthcare providers [21]. Mullany et al. in a clinical trial in Nepal found that male education along with their wives promoted men's preparation for childbirth (including planning to transfer the pregnant women to the hospital at delivery time, planning for emergencies and etc.) [38].

The results of the present study showed that the mean score of men's knowledge and attitude about participation in perinatal care in group- based training along with text messaging were significantly higher than in CDbased training after the intervention. However, the mean score of men' s knowledge and attitude in CD- based training were not significantly different from the control group. It seems that the reason for the lack of significant changes in the mean scores of men's knowledge and attitude in CD-based training group is due to the lack of sufficient opportunity to make adequate use of the educational content of the CD due to men's busy. In this regard, the findings of the present study revealed that the majority of participating men were the sole source of family income and their wives in most cases were housewives. Meanwhile, the disadvantages of $\mathrm{CD}$ include lack of face-to-face communication between the trainer and learner, no exchange of information and experiences between group members as well as between the trainer and the learner, which in turn causes less motivation [39]. Baldwin et al. showed that fathers wanted more guidance and support around the preparation for fatherhood, and partner relationship changes [40]. Also, Sarkadi et al. concluded that there is enough support to urge both professionals and policy makers to improve circumstances for involved fathering [41]. Based on the results of the present study, group- based training along with text messaging could be used as an appropriate method to improve men's knowledge and attitude about participation in perinatal care.

\section{Strengths and limitations}

One of the strengths of this study is the implementation of educational intervention on men's knowledge and attitude about participation in perinatal care, for the first time, and almost all the principles of clinical trial, were observed to prevent selection bias. In the present study, coordinating with participating men to attend clinics for trial registration and also attend sessions in group- based training required frequent phone calls, which was time consuming. In this regard, 20 days before the intervention, participating men were repeatedly contacted and invited to register. Also, reminder text messages were sent to attend the training sessions on time.

One of the limitations of this research is individual differences between participating men in learning educational materials; therefore, this may affect data collection. The results of this trial may not be generalizable, because other settings, with different participants, and differing extents of training or motivation of healthcare providers could produce different results.

Table 4 Pairwise comparison in terms of the mean scores of men's knowledge and attitude after the intervention

\begin{tabular}{|c|c|c|c|c|c|c|}
\hline \multirow[t]{2}{*}{ Variable } & \multicolumn{2}{|c|}{$\begin{array}{l}\text { Group- based training along with text } \\
\text { messaging to the control group }\end{array}$} & \multicolumn{2}{|c|}{$\begin{array}{l}C D \text { - based training to } \\
\text { the control group }\end{array}$} & \multicolumn{2}{|c|}{$\begin{array}{l}\text { Group- based training along with text } \\
\text { messaging to the CD- based training }\end{array}$} \\
\hline & $\begin{array}{l}\text { Mean difference } \\
(\% 95 \mathrm{Cl})\end{array}$ & $P$-value & $\begin{array}{l}\text { Mean difference } \\
(\% 95 \mathrm{Cl})\end{array}$ & $P$-value & $\begin{array}{l}\text { Mean difference } \\
(\% 95 \mathrm{Cl})\end{array}$ & $P$-value* \\
\hline Knowledge & $4.6(3.1-6.2)$ & $>0.001$ & $1.4(-0.19-2.9)$ & 0.103 & $3 / 3(1.7-4.8)$ & $>0.001$ \\
\hline Attitude & $3.8(0.5-7.3)$ & 0.021 & $0.4(-2.9-3.8)$ & 0.986 & $3.4(0.13-6.7)$ & 039/0 \\
\hline
\end{tabular}

* $P<0.05$ was considered significant 


\section{Conclusion}

Based on the results, group- based training along with text messaging was more effective in improving the knowledge and attitude of men about participation in perinatal care compared to $\mathrm{CD}$ - based training. It is worth noting that educational interventions should be designed and implemented in accordance with the real life conditions of people. Although, in the present study the educational content was the same in both training methods, participating men did not adequate use the educational content of the CDs and as a result, the use of $C D$ - based training was not associated with positive results in promoting men's knowledge and attitude about perinatal care. It seems that despite the small number of participants in this study, holding groupbased training classes on holidays and in the men's leisure time, has provided a great opportunity for them to learn and exchange ideas, followed by sending health text messages to continue learning and thus improve their knowledge and attitude about participation in perinatal care. Therefore, group- based training along with text messaging could be used as an appropriate method by policymakers and health planners in designing effective, culture-based educational interventions in men in the workplace, health centers and childbirth preparation classes.

\section{Abbreviations}

ICPD: International conference on population and development; MDGs: Millennium development goals; CD: Compact disc; ICC: Intra-cluster correlation coefficient; ANCOVA: Analysis of covariance; ANOVA: Analysis of variance; Cl: Confidence interval

\section{Acknowledgments}

We should thank the Vice-chancellor for Research of Isfahan University of Medical Sciences and Tabriz University of Medical Sciences for their support. Also we should thank the men, healthcare providers and health services managers of Tabriz for their sincere participation in the research.

\section{Authors' contributions}

All the authors contributed to the conception and design of the study. VF drafted the first version of the manuscript. MN, ZF, and MM revised the manuscript. MN critically reviewed the manuscript for important intellectual content. All authors approved the final version.

\section{Funding}

This research was conducted with the financial support of Isfahan University of Medical Sciences and Tabriz University of Medical Sciences, Research proposal No: 395599. The funding agency played no role in the design of the study and collection, analysis, and interpretation of data and in writing the manuscript.

\section{Availability of data and materials}

The datasets generated and/or analysed during the current research are not publicly available as individual privacy could be compromised but are available from the corresponding author on reasonable request.

\section{Ethics approval and consent to participate}

The Ethics Committee of the Isfahan University of Medical Sciences in Isfahan, Iran approved the protocol of this study (code number: IR.MUI.Rec.1395.3.599). Written informed consent is taken from each participant.

\section{Consent for publication}

Not applicable.

\section{Competing interests}

The authors declare that they have no competing interests.

\section{Author details}

${ }^{1} 29$ Bahman Hospital Research Center, Iranian Social Security Organization, Tabriz, Iran. ${ }^{2}$ Department of Midwifery and Reproductive Health, School of Nursing and Midwifery, Isfahan University of Medical Sciences, Isfahan, Iran.

${ }^{3}$ Social Determinants of Health Research Center, Tabriz University of Medical Sciences, Tabriz, Iran. ${ }^{4}$ Department of Community Medicine, Medicine

School, Isfahan University of Medical Sciences, Isfahan, Iran.

Received: 13 April 2020 Accepted: 2 December 2020

Published online: 09 December 2020

\section{References}

1. Kaye DK, Kakaire O, Nakimuli A, Osinde MO, Mbalinda SN, Kakande N. Male involvement during pregnancy and childbirth: men's perceptions, practices and experiences during the care for women who developed childbirth complications in Mulago hospital, Uganda. BMC Pregnancy Childbirth. 2014; 14:54.

2. Firouzan V, Noroozi M, Farajzadegan Z, Mirghafourvand M. Participation of father in perinatal care: a qualitative study from the perspective of mothers, fathers, caregivers, managers and policymakers in Iran. BMC Pregnancy Childbirth. 2018;18(1):297.

3. Yargawa J, Leonardi-Bee J. Male involvement and maternal health outcomes: systematic review and meta- analysis. JECH. 2015;69(6):604-12.

4. Davis J, Luchters S, Holmes W. Men and maternal and newborn health: benefits, harms, challenges and potential strategies for engaging men. Australia: Compass; 2012.

5. Redshaw M, Henderson J. Fathers' engagement in pregnancy and childbirth: evidence from a national survey. BMC Pregnancy Childbirth. 2013;13(1):70.

6. Firouzan V, Noroozi M, Farajzadegan Z, Mirghafourvand M. Barriers to men's participation in perinatal care: a qualitative study in Iran. BMC Pregnancy Childbirth. 2019;19(1):45.

7. Ergo A, Eichler R, Koblinsky M, Shah N. Strengthening health systems to improve maternal, neonatal and child health outcomes: a framework. Washington, D.C: MCHIP, USAID; 2011.

8. Morfaw F, Mbuagbaw L, Thabane L, Rodrigues C, Wunderlich AP, Nana P, et al. Male involvement in prevention programs of mother to child transmission of HIV: a systematic review to identify barriers and facilitators. Syst Rev. 2013;2(1):5.

9. Ditekemena J, Koole O, Engmann C, Matendo R, Tshefu A, Ryder R, et al. Determinants of male involvement in maternal and child health services in sub-Saharan Africa: a review. Reprod Health. 2012;9(1):32.

10. Nkuoh GN, Meyer DJ, Tih PM, Nkfusai J. Barriers to men's participation in antenatal and prevention of mother-to-child HIV transmission care in Cameroon, Africa. JMWH. 2010;55(4):363-9.

11. Asefa F, Geleto A, Dessie Y. Male partners involvement in maternal ANC care: the view of women attending ANC in Hararipublic health institutions, eastern Ethiopia. SJPH. 2014;2(3):182-8.

12. Johnsen H, Stenback P, Hallden BM, Svalenius EC, Persson EK. Nordic fathers' willingness to participate during pregnancy. J Reprod Infant Psychol. 2017; 35(3):223-35.

13. Suandi D, Williams $P$, Bhattacharya $S$. Does involving male partners in antenatal care improve healthcare utilization? Systematic review and metaanalysis of the published literature from low- and middle-income countries. Int Health. 2020;12(5):484-98.

14. Mortazavi F, Mirzaii K. Reason of barriers to and outcomes of husbands' involvement in prenatal and intrapartum care program based on midwives' experiences: a qualitative study. AMUJ. 2012;15(60):104-15.

15. Mangeni JN, Nwangi A, Mbugua S, Mukthar V. Male involvement in maternal healthcare as a determinant of utilisation of skilled birth attendants in Kenya. East Afr Med J. 2012;89(11):372-83.

16. Lewis S, Lee A, Simkhada P. The role of husbands in maternal health and safe childbirth in rural Nepal: a qualitative study. BMC Pregnancy Childbirth. 2015;15:162. 
17. Nesane K, Maputle SM, Shilubane H. Male partners' views of involvement in maternal healthcare services at Makhado municipality clinics, Limpopo Province, South Africa. Afr J Prim Health Care Fam Med. 2016;8(2):e1-5.

18. Levtov R, Gagg NV, Kaufman M, Barker G. State of the world's fathers. A mencare advocacy publication, 2015. Retrieved from: https://www.atria.nl/ epublications/IAV_B00110812.pdf.

19. Midhet F, Becker S. Impact of community-based interventions on maternal and neonatal health indicators: results from a community randomized trial in rural Balochistan, Pakistan. Reprod Health. 2010;7:30.

20. Adeleye OA, Okonkwo CA. Changes in men's knowledge \& attitudes following health education on their role in preventing maternal deaths: an exploratory survey in a Nigerian community. Soc Med. 2016;10:41-51.

21. Bishwajit G, Tang S, Yaya S, Ide S, Fu H, Wang M, et al. Factors associated with male involvement in reproductive care in Bangladesh. BMC Public Health. 2017;17:3.

22. Daniele, M. Involving men in maternity care in Burkina Faso: an intervention study. PhD thesis, London school of hygiene \& tropical medicine, 2017.

23. United Nation Population Fund (UNFPA). International conference on population and development. 2014. Retrieved from: http://www.unfpa.org/ icpd/icpdprogramme.cfm. Accessed 6 Apr 2020.

24. Saif A. Learning psychology and education. Tehran: Duran publishing company; 2011. [In Persian].

25. Jayatilleke AC, Yoshikawa K, Yasuoka J, Poudel KC, Fernando N, Jayatilleke $\mathrm{AU}$, et al. Training Sri Lankan public health midwives on intimate partner violence: a pre- and post-intervention study. BMC Public Health. 2015;15: 331.

26. Bayrami M, Zahmatyar H, Bahadori KJ. Prediction strategies to coping with stress in the pregnancy women with first experience on the based factors hardiness and social support. IJNR. 2010;7(27):1-9.

27. Littleton HL, Bye K, Buck K, Amacker A. Psychosocial stress during pregnancy and perinatal outcomes: a meta-analytic review. J Psychosom Obstet Gynecol. 2010;31(4):219-28.

28. Mansoorian M, Rastegari-Mehr B, Ghorbani M, Shafieian Z, Safari O, Moradi $\mathrm{S}$, et al. Study the relationship between internet-related lifestyle and loneliness and social support among internet users in Ilam University of Medical Sciences. Jorjani Biomed J. 2015;3(1):114-26.

29. Nazari S, Salari P, Mazlom R, Mahram B. Comparison of social support in the first and second month of postpartum in multiparous. Community Health J. 2014;8(2):1-9.

30. Saeedi $\mathrm{H}$, Ashoori J. The relationship between social capital, perceived social support and organizational citizenship behavior, and mental health, case study of police force employees in south eastern Tehran. Mil Caring Sci. 2016;3(2):90-9.

31. Kim TH, Connolly JA, Tamim H. The effect of social support around pregnancy on postpartum depression among Canadian teen mothers and adult mothers in the maternity experiences survey. BMC Pregnancy Childbirth. 2014;14(1):162.

32. Nilsson IM, Strandberg-Larsen $\mathrm{K}$, Knight $\mathrm{CH}$, Hansen AV, Kronborg $\mathrm{H}$. Focused breastfeeding counselling improves short-and long-term success in an early-discharge setting: a cluster-randomized study. Matern Child Nutr. 2017;13(4):E12432.

33. Sharifirad GR, Golshiri P, Shahnazi H, Barati M, Hasanzadeh A, Charkazi A, et al. The impact of educational program based on BASNEF model on breastfeeding behavior of pregnant mothers in Arak. J Arak Uni Med Sci. 2010;13(1):63-70.

34. Froehlich J, Boivin M, Rice D, Mcgraw K, Munson E, Walter KC, et al. Influencing university students' knowledge and attitudes toward breastfeeding. J Nutr Educ Behav. 2013;45(3):282-4.

35. Alawode G. Involving men in maternal health through telephone technology. APHA 142 nd annual meeting \& expo, New Orleans. November 15-19, 2014.

36. Allport BS, Johnson S, Aqil A, Labrique AB, Nelson T, Kc A, et al. Promoting father involvement for child and family health. Acad Pediatr. 2018;18(7):74653.

37. Kerstis B, Wells MB, Andersson E. Father group leaders' experiences of creating an arena for father support - a qualitative study. Scand J Caring Sci. 2018;32(2):943-50.

38. Mullany BC, Becker S, Hindin M. The impact of including husbands in antenatal health education services on maternal health practices in urban Nepal: results from a randomized controlled trial. Health Educ Res. 2006;22: $166-76$
39. Kardan BE, Bakhshandeh H, Nikpajouh A, Elahi E, Haghjoo M. Comparison of the effect of education through lecture and multimedia methods on knowledge, attitude, and performance of cardiac care. IJCN. 2016;4(4):6-13.

40. Baldwin S, Malone M, Sandall J, Bick D. Mental health and wellbeing during the transition to fatherhood a systematic review of first time fathers' experiences. JBI Database System Rev Implement Rep. 2018;16(11):2118-91.

41. Sarkadi A, Kristiansson R, Oberklaid F, Bremberg S. Fathers' involvement and children's developmental outcomes: a systematic review of longitudinal studies. Acta Pediatr. 2008:97(2):153-8.

\section{Publisher's Note}

Springer Nature remains neutral with regard to jurisdictional claims in published maps and institutional affiliations.
Ready to submit your research? Choose BMC and benefit from:

- fast, convenient online submission

- thorough peer review by experienced researchers in your field

- rapid publication on acceptance

- support for research data, including large and complex data types

- gold Open Access which fosters wider collaboration and increased citations

- maximum visibility for your research: over 100M website views per year

At BMC, research is always in progress.

Learn more biomedcentral.com/submissions 